\title{
Programas de marketing social: proposição e exame de uma estrutura conceitual de avaliação de resultados
}

\author{
Paulo Ricardo dos Santos Meira \\ Senado Federal \\ Cristiane Pizzutti dos Santos \\ Universidade Federal do Rio Grande do Sul
}

\begin{abstract}
A área de marketing tem sido cada vez mais demandada a prestar contas de suas ações, na forma de avaliação dos investimentos realizados. No marketing social não é diferente. O presente estudo examinou propostas de avaliação de programas de marketing social, em busca do que seria uma estrutura conceitual ideal para esse tipo de avaliação, a partir da literatura, prática de mercado, opinião de experts e exame empírico da proposta em dois diferentes estudos de caso, o programa Novo Sinal, da Prefeitura Municipal de Porto Alegre e os programas de imunização do Centro Estadual de Vigilância em Saúde do Governo do Rio Grande do Sul. A metodologia, qualitativa em sua essência, fez uso da técnica Delphi, entrevistas em profundidade e estudo de casos. A estrutura conceitual desenvolvida engloba as dimensões de avaliação de Input, Processo e Resultados, com respectivas variáveis e indicadores para cada dimensão, e ao longo de cujas dimensões a avaliação ética se faz presente, mas ainda de difícil avaliação na prática cotidiana dos profissionais de marketing social.
\end{abstract}

Palavras-chave: marketing social; mudança social planejada; avaliação.

Social marketing programs: proposition and examination of a conceptual framework for results evaluation

Marketing, as a whole, has been demanded on its accountability to give evidence of good practice in return of investments. The same situation challenges social marketing. This paper examined evaluation structural frameworks brought by marketing literature, in quest of the "ideal" framework of evaluation, based on academic articles review, market actual practice, experts opinion, and an empirical examination of the proposal in two real cases, the "pedestrian crossing new signal case" of Porto Alegre City Hall, and the Immunological Program of the Public Health State Center (Cesv/RS) of the Government of Rio Grande do Sul. The essentially qualitative methodology involved Delphi research, in-depth interviews and case studies. The structural framework eventually developed integrates Input,

Artigo recebido em maio 2010 e aceito em jul. 2011. Paulo Ricardo dos Santos Meira agradece ao Detran (RS) e ao UniRitter pelo apoio recebido para a pesquisa e titulação. 
Process and Outcomes dimensions of evaluation, each one with its due variables, indicators and forms or measurement. The ethical issue is pervasive in all dimensions, but not with a easy way of assessment in everyday's practice of social marketers.

KEY WORDS: social marketing; planned social change; evaluation.

Commercial marketers have very clear, relatively simple metrics by which to guide and evaluate their efforts, such as sales, market share, and profits. Nonprofit marketers are often challenged to achieve difficult-tomeasure goals like reducing spousal abuse, increasing physical activity, or making the end-of-life years less stressful. Such challenges are hard to measure, very long term, and subject to all sorts of influences outside the marketer's control.

(Alan Andreasen, 2000)

\section{Introdução}

Em cada sociedade, segundo Sheth e Frazier (1982:16), o comportamento de alguns indivíduos não está em sintonia com os interesses de longo prazo da sociedade como um todo. Exemplos vão desde a falta de uso de contraceptivos em países com excesso de densidade populacional, a produção excessiva de lixo à condução perigosa ao volante. Nesse contexto, dá-se a importância do marketing social, entendido como o uso das ferramentas de marketing para a mudança social planejada (Andreasen, 2003). No entanto, a avaliação de programas de marketing social apresenta grandes desafios.

Por exemplo, supondo-se que uma determinada campanha voltada à redução do tabagismo na juventude tivesse mostrado uma redução no número de fumantes. Essa seria a única medida de sucesso? E se o número de fumantes não tivesse diminuído, mas uma análise mostrasse que os jovens estavam fumando menos cigarros por dia? Ou que a maioria dos jovens conseguisse se lembrar da mensagem da campanha? Ou, ainda, se boa parte dos que tivessem parado por conta da campanha voltasse a fumar? A campanha poderia ainda ser considerada um sucesso? Essas questões são apresentadas por Kotler, Roberto e Lee (2002), para trazer à tona a problemática de que avaliação de desempenho de programas de marketing social não é algo óbvio, como poderia à primeira vista parecer, e se configura no tema de aprofundamento deste artigo.

Em artigo de 1999, Day e Montgomery defenderam que um dos desafios para o marketing acadêmico, nos anos a seguir, seria o desenvolvimento de mecanismos de avaliação que pudessem ser usados para ajudar acadêmicos, executivos e órgãos governamentais a julgar o desempenho das atividades de marketing em relação a padrões absolutos e relativos. Se a escolha e utilização de formas adequadas de avaliação é um desafio para o marketing comer- 
cial (Rust et al., 2004), o é ainda mais em uma área em particular, denominada desde os anos 1970 "marketing social" (Kotler, Roberto e Lee, 2002), com métricas menos claras do que o marketing tradicional, ou comercial (Andreasen, 2003), e em muitos pontos mais desafiadora do que o marketing voltado à venda de bens e serviços comerciais, cujo foco se baseia, entre outros aspectos, no retorno e impacto financeiro sobre a empresa (Rust et al., 2004:77).

O presente trabalho está focado no marketing social, tal como definido pelo Social Marketing Institute: "é o planejamento e implementação de programas desenhados para criar mudança social a partir de conceitos advindos do marketing comercial". ${ }^{1}$ Assim, não é foco deste artigo a prática do marketing ligado a causas, cujo intuito é em geral comercial (pela qualificação da imagem da empresa junto aos diversos públicos de interesse), nem o marketing societal (entendido aqui como a prática do marketing comercial com os devidos cuidados no plano social e ambiental). Tampouco neste trabalho compartilha-se a ideia de marketing social como o uso de redes sociais on-line tais como o Facebook ou MySpace, conforme Voight (2007) ou McGeveran (2009); este, em nossa concepção, deve ser tratado simplesmente como marketing em redes sociais.

Alguns esquemas de avaliação de programas de marketing social têm sido propostos pela literatura, como o de "Impacto e Ética", de Kotler e Roberto (1992), o de Weinreich (1999), de "Resultados e Processos", de Kotler, Roberto e Lee (2002), de Varcoe (2004) e o de "Produção, Resultados e Impacto", de Kotler e Lee (2008). Ressalta-se, no entanto, que, até onde se sabe, tais esquemas consistem de proposições teóricas e prescritivas, sem um exame empírico referente a elas. Conforme corrobora McDermott (2004:20), "Avaliação em marketing social ainda é uma ciência jovem". Dessa forma, entende-se que há espaço para análise crítica e proposições de avanços. Por conseguinte, propõe-se aqui a construção de uma estrutura conceitual de avaliação - conforme Rossiter (2001:13), que define "structural frameworks" como "modelos não causais, que podem ser úteis no cotidiano organizacional como quadros de referência para a atuação dos profissionais" —, com suas dimensões e respectivos indicadores, a partir de um estudo exploratório e qualitativo.

Nesse sentido, a questão central que se busca responder neste artigo é: qual a melhor forma de avaliação de resultados de programas de marketing social?

\section{Fundamentação teórica}

Apresentam-se nesta seção as principais contribuições de autores da área ao tema pesquisado, estando organizada em: (a) fundamentos e considerações éticas do marketing social e (b) avaliação do desempenho em programas de marketing social, passando pelas principais propostas de estruturas de avaliação da literatura.

\footnotetext{
${ }^{1}$ Disponível em: <www.social-marketing.org/sm.html>. Acesso em: 17 ago. 2009.
} 


\subsection{Fundamentos e considerações éticas do marketing social}

Apesar de Pringle e Thomson (2000) utilizarem as expressões "marketing social" e "marketing relacionado a causas" como sinônimas, cabe distingui-las. O marketing de causas sociais (MCS) ou marketing relacionado a causas (MRC) é uma parceria entre empresas e organizações da sociedade civil que utilizam o poder de suas marcas em benefício mútuo, e que, eventualmente, sofre críticas por explorar causas simpáticas ao público com objetivos de melhorar o desempenho comercial (Drumwright, 1996:83). O MRC pode ser útil à imagem — e desempenho comercial - da empresa, desde que os valores da causa em questão estejam alinhados aos valores dos consumidores (Machado e Damacena, 2006). O benefício, no MRC, vai além da empresa em si: se dá tanto para a empresa quanto para a causa de caridade, e ainda para o cliente, mas "a ênfase é em marketing" (Smith e Higgins, 2000:307). Conforme reforça Fontes (2008:76), "no caso de uma empresa condicionar sua atuação social com o objetivo de agregar valor social ao seu produto, ela não [destaque nosso] estará fazendo marketing social". Para o autor, a diferença está no foco do "P" de produto da estratégia: se o foco principal é o produto comercializado pela empresa, e a causa social está em um segundo plano, trata-se, nesse caso, de marketing comercial ligado a uma causa.

Marketing social, por seu turno, costuma ser praticado por governos, agências de financiamento e organizações da sociedade civil bem mais do que por empresas (Fontes, 2008). Seu objetivo é conscientizar ou sensibilizar as pessoas a respeito de um tema de natureza social, ou buscar uma mudança de comportamento social. Por sua vez, "marketing societal" pode ser entendido como um processo no qual as funções e responsabilidades de um determinado segmento de marketing são vistas como inter-relacionadas com os outros segmentos da estrutura social. Assim, marketing relaciona-se com os ambientes legal, político, educacional e com a comunidade em geral, ou seja, há uma responsabilidade para com indivíduos outros que não somente os consumidores (Bartels, 1974:74). Como trazem Kerin e colaboradores (2008:21), o conceito de marketing societal é a "visão de que as organizações devem satisfazer as necessidades dos consumidores de forma que proporcionem o bem-estar para a sociedade" - produzindo, por exemplo, com menor utilização de recursos naturais, promovendo reciclagem, reinvestindo socialmente - , diferindo, por conseguinte, do conceito de "marketing social" no presente entendimento da literatura.

Entre as definições atuais de marketing social tem-se: "o uso dos princípios e técnicas de marketing para influenciar um público-alvo a voluntariamente aceitar, rejeitar, modificar ou abandonar um comportamento para o benefício de indivíduos, grupos ou da sociedade como um todo" (Kotler e Lee, 2008:207).

Desta forma, a perspectiva de marketing social para mudança social planejada tem sido utilizada com êxito em diferentes programas (Gordon et al., 2006). Não obstante, ainda que o marketing social vise a um maior bem-estar social, os agentes de mudança social (governos, instituições) enfrentam desafios éticos complexos (Kirby e Andreasen, 2001; Cooksy, 2009) que, na percepção de Brenkert (2002), vão além das questões morais enfrentadas pelas demais formas de marketing, tais como acusações de manipulação e desonestidade, necessidade de justiça e questões de intrusividade. As implicações éticas das atividades de marketing 
social têm recebido pouca atenção, de uma forma geral, como argumentam Murphy e Bloom (1992) e Brenkert (2002), mas essas implicações são importantes. Por exemplo, é aceitável exagerar-se o risco ou incutir o medo em campanhas sociais, se isso salvará mais vidas (Duke et al., 1993)? E se melhorar o padrão de vida de um grupo tiver impacto negativo em outro? Como uma campanha de marketing social respeita a cultura de um grupo se está justamente buscando uma mudança essencial em sua forma de ser ou agir? Questões éticas impactam igualmente a segmentação de clientes, por exemplo (Andreasen, 2003): deveriam ser investidos recursos limitados em públicos-alvo prontos para mudar se tais segmentos não são os mais pobres ou mais necessitados membros de uma sociedade?

Duke e colaboradores (1993) propuseram um processo de avaliação de ética para as comunicações de marketing social, tendo por foco os apelos de medo, que, na visão de Kirby e Andreasen (2001), tem o potencial de generalização para um largo espectro de dilemas no marketing social. O esquema de análise de Duke e colaboradores (1993) integra múltiplas filosofias éticas bem como múltiplos grupos de interesse, e foi denominado de Matriz de Reflexão Ética sobre Efeitos. Em suma, os autores explicam que os apelos de medo na publicidade podem ser avaliados ao examinarem-se os benefícios e custos potenciais que qualquer stakeholder poderia provavelmente experienciar pela exposição à peça (campanha) de comunicação com o apelo de medo. Cada benefício e desvantagem, conforme Duke e colaboradores (1993), são avaliados em relação a diferentes abordagens de questionamentos éticos, a saber:

a) Utilitarismo: princípio ético que foca em atingir o máximo bem (ou benefício) para o maior número de pessoas.

b) Regra de Ouro: vê o comportamento ético como aquele que trata os demais assim como o ator ou agente ético gostaria de ser tratado.

c) Abordagem Kantiana: estabelece que todos os indivíduos têm direitos básicos (exemplos: privacidade, tratamento justo e assim por diante).

d) Interesse Próprio Iluminado: propõe que comportamento ético é aquele que busca maximizar benefícios pessoais enquanto minimiza o prejuízo aos demais.

Essa matriz foi ampliada por Kirby e Andreasen (2001) de forma a avaliar não somente a comunicação, mas cada um dos elementos do composto de marketing, tendo se concentrado nas abordagens éticas do "utilitarismo" e do "Interesse Próprio Iluminado", uma vez que a Regra de Ouro e a Abordagem Kantiana se concentram mais fortemente na questão individual, e o foco de atuação do profissional de marketing social "é o ganho societal, e não tanto os direitos individuais" (Kirby e Andreasen, 2001:20).

Na seção seguinte expõem-se as formas de avaliação de resultados propostas por diferentes autores.

\subsection{Avaliação de resultados em marketing social}

Um programa de marketing social deveria conter, para Kotler, Roberto e Lee (2002:142-143), objetivos comportamentais (o que se deseja que as pessoas façam), objetivos cognitivos (o que 
se deseja que elas saibam) e objetivos de crença (o que se deseja que elas acreditem), e na medida do possível os objetivos devem ter metas mensuráveis, para uma avaliação final dos resultados. A fim de que se saiba se esses objetivos estão sendo atingidos, da mesma forma como se busca a mensuração do desempenho das atividades do marketing tradicional — entenda-se "comercial" — , tem sido dada importância igualmente à avaliação do desempenho de programas de marketing social. Diferentes estruturas de avaliação desses programas sociais têm sido trazidas na literatura e serão apresentadas, sucintamente, a seguir.

\subsubsection{Estrutura de Kotler e Roberto (1992)}

Kotler e Roberto (1992) asseveraram que a avaliação de um programa de marketing social teria basicamente duas vertentes: a do impacto e a da ética. Na faceta do impacto, a questão principal é "Será que a campanha gerou as mudanças pretendidas e será que outros fatores acarretaram a mudança?". Da mesma forma, os programas de marketing social devem passar por uma "avaliação ética", na qual três critérios éticos distintos devem ser levados em conta: o primeiro critério é o da consequência ética do impacto de um programa; o segundo, "mudança correta", diz respeito à correção ou desejabilidade dos objetivos do programa, por exemplo, o caráter ético da segmentação e a escolha de adotantes selecionados como alvo; o terceiro engloba a questão ética dos meios-fins: "a forma correta", ou seleção ética de meios adequados para atingirem-se os objetivos do programa (Kotler e Roberto, 1992). Esta abordagem tem o diferencial de incorporar a questão ética à avaliação do marketing social, mas, por outro lado, traz, sob a mesma denominação de "impacto", indicadores como a "eficiência de execução", que é um aspecto mais ligado a processo, e não a resultado. Impacto, assim, leva à ideia de uma avaliação somativa, enquanto vê-se, na literatura, a importância de uma avaliação formativa, de correção de rumos durante o processo de execução do programa de marketing social.

Figura 1

\section{Dimensões de avaliação de programas de marketing social}

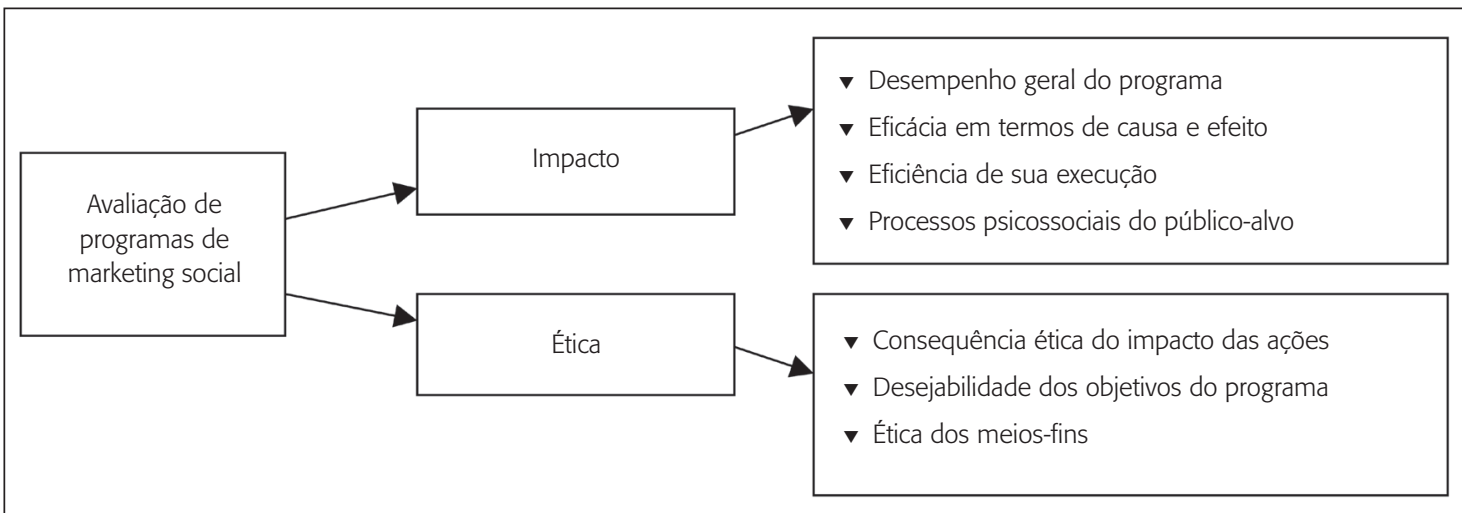

Fonte: Kotler e Roberto (1992). 


\subsubsection{Estrutura de Weinreich}

Weinreich (1999) propôs que programas de marketing social fossem realizados com as seguintes etapas: (a) planejamento do programa como um todo; (b) desenvolvimento de mensagem e materiais adequados; (c) pré-teste desse material e mensagens; (d) implementação do programa e (e) avaliação: recomendada pela autora em duas grandes frentes: avaliação de processo e avaliação de resultados.

Contudo, a autora (1999:204) ressalva que, apesar de a avaliação ser a última etapa em sua proposta, ela permeia todo o programa de marketing social, com constante feedback em cada etapa para melhoramento do programa, e que se inicia com uma avaliação formativa durante o planejamento ("o que deveríamos fazer?"), transforma-se em uma avaliação de processo durante a implementação (“como estamos fazendo?") e culmina em uma avaliação somativa ("conseguimos fazê-lo?").

A avaliação somativa final deveria desdobrar-se, conforme Weinreich (1999), em dois aspectos: avaliação de resultados, em termos de respostas do público-alvo, e avaliação do impacto, que vai além da mudança comportamental individual para abranger as consequências sociais e de saúde pública advindas do programa de marketing social. Um ponto fraco dessa abordagem é o de que "impacto", na percepção de outros autores, é uma categoria pertencente aos "resultados".

\subsubsection{Estrutura de Kotler, Roberto e Lee}

Em 2002, Kotler, Roberto e Lee (2002:327-332) advogam que, mais comumente, se mensuram os processos e os resultados, conforme figura 2 a seguir. Para os autores, as medidas de processo são as que se encontram sob o controle do programa de marketing social, enquanto as de resultado referem-se aos objetivos que o programa estabelece, tais como mudanças comportamentais. Os autores citam (Kotler, Roberto e Lee, 2002:327) que uma terceira consideração, a das consequências éticas, é tratada em separado, sem fazer parte das medições principais.

Os autores ressalvam que as medidas de resultado são os resultados pretendidos, planejados; dessa forma, reconhecem a existência de eventuais resultados não planejados, nem mesmo desejados, a partir da execução dos programas de marketing social, como ao se promover uso de materiais recicláveis aumenta-se bastante o volume de uso desses materiais, justamente pela despreocupação por serem, já, reciclados.

Ressalte-se que a simplificação de apenas duas dimensões, de medidas de processo e medidas de resultado, não permite um desdobramento dos resultados em duas diferentes frentes que se complementam, mas ainda assim são vertentes distintas, a saber, as respostas do público-alvo e o impacto socioeconômico resultante do programa. Outra limitação nessa proposição é o de que cobertura da mídia é considerada uma medida de processo - e não de resultado - , pois nem sempre o espaço na mídia é conquistado na mesma proporção do esforço de assessoria de imprensa realizado (este sim, um processo da entidade organizadora). 
Figura 2

Avaliação de programas de marketing social

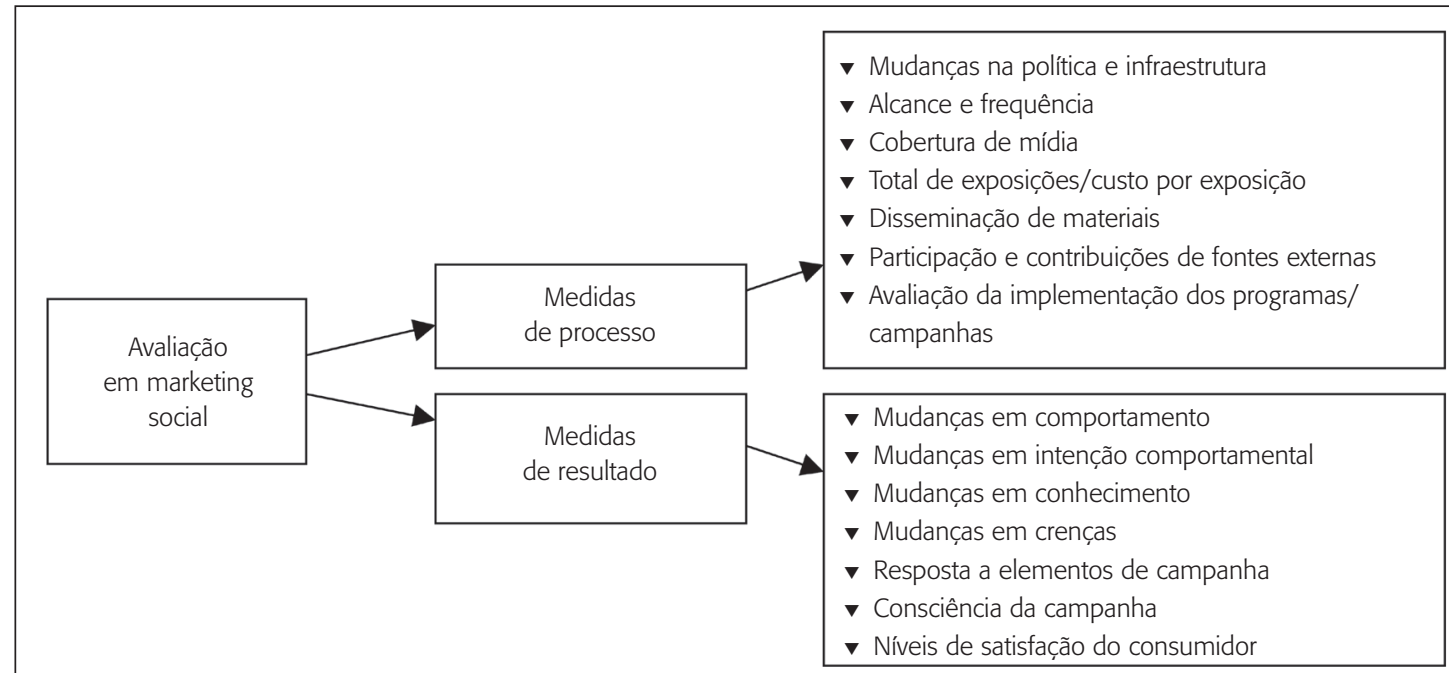

Fonte: adaptado de Kotler, Roberto e Lee (2002).

\subsubsection{Estrutura de Kotler e Lee}

Para examinar-se a estrutura conceitual de avaliação de programas de marketing social de Kotler e Lee (2008:286), cabe contextualizar o que os autores apresentam como questões básicas para os programas: (a) Por que você está conduzindo essa mensuração e para quem?; (b) $\mathbf{O}$ que [destaque nosso] você estará medindo? (c) Como você irá conduzir essas mensurações? (d) Quando essas mensurações serão feitas? (e) Quanto isso custará?

No segundo item, a saber, o das dimensões de "o que medir", os autores (2008:286-289) propõem a mensuração de uma ou mais de três categorias: produção, resultados e/ou impactos, como na figura 3 a seguir.

A primeira categoria - produção — refere-se, assim, ao processo, ao esforço da entidade; a segunda — resultados — , a um nível comportamental individual ou coletivo, uma resposta ao esforço de produção; a terceira — impacto — , a esferas econômicas, culturais, ambientais, sociais e afins. Contudo, há possibilidades de melhoria nessa proposta, uma vez que, semanticamente, "impacto" também é um "resultado" — em sua obra, Fontes (2008:112) trata "impacto" como algo "em relação aos resultados alcançados pelo programa", não deixando claro se o entende como resultado, ou efeitos de mais longo prazo; por conseguinte, uma melhor denominação da segunda dimensão seria a de "respostas". Outrossim, questões como o "número de exposições em outros canais de comunicação" e "menções e tempo no ar" na mídia não são fatores controláveis pela agência social, sendo na verdade resultado do esforço, 
mas não o esforço em si. Dessa forma, não deveriam estar entre as mensurações de produção. Percebe-se que, assim como em sua proposta com Roberto e Lee, de 2002, Philip Kotler não manteve nesta versão a dimensão da ética defendida em 1992 com Roberto.

Figura 3

O que medir em marketing social

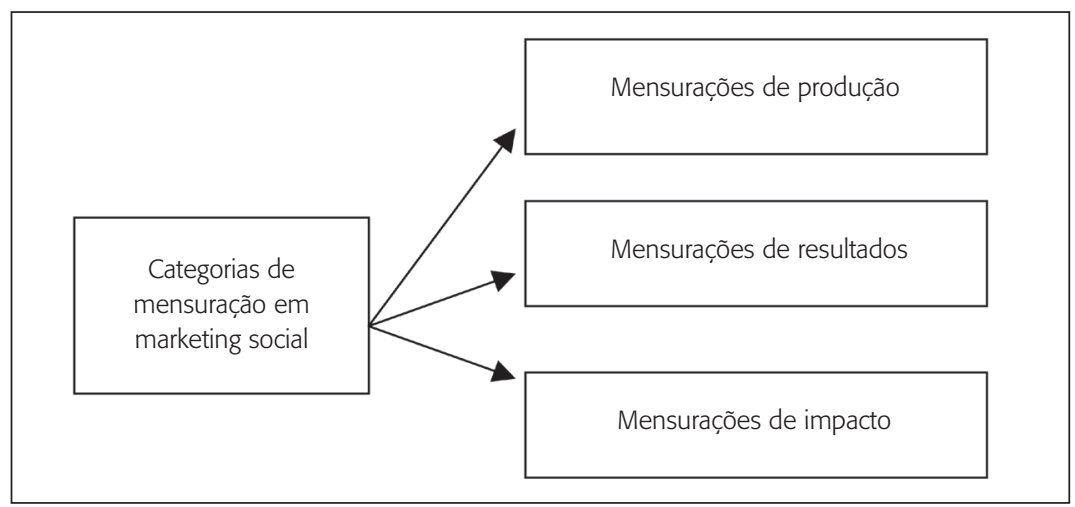

Fonte: adaptado de Kotler e Lee (2008)

Apesar de Gill, Flynn e Reissing (2005) trazerem contribuições quanto a dimensões de avaliação, não apresentam uma estrutura comparável às aqui sumarizadas, tendo seu foco como o de um checklist de governança corporativa para instituições sem fins lucrativos. Assim, suas contribuições são citadas neste artigo, mas não na forma de uma estrutura junto às de marketing social, diretamente.

De um modo geral, as diferentes propostas de avaliação de programas de marketing social apresentadas nesta seção do trabalho constituem-se como subsídios para o propósito deste estudo, que pretende preencher as lacunas identificadas. Dessarte, a partir das fragilidades e oportunidades das categorizações anteriores, as quais, salvo engano, foram desenvolvidas sem um embasamento empírico mais consistente que as valide, delineia-se aqui a oportunidade de desenvolvimento de uma estrutura conceitual de avaliação em programas de marketing social, de caráter abrangente e aplicável por planejadores e executores de políticas públicas e programas sociais.

\section{Método}

Em face do caráter exploratório deste estudo, o delineamento da pesquisa é eminentemente qualitativo. Os métodos qualitativos são usados para explorar áreas pouco conhecidas, ou para se explorar mais profundamente algo previamente conhecido (Strauss e Corbin, 2008), o que se configura no caso da temática deste estudo, que aborda as dimensões de avaliação de 
ações de marketing social, sobre as quais há literatura acadêmica (Doner, 2003) e gerencial (Kotler, Roberto e Lee; 2002; Kotler e Lee, 2008), mas ainda em caráter incipiente.

Para as etapas de construção e exame da estrutura conceitual foram utilizados diferentes métodos. O uso de distintos métodos é previsto e incentivado na literatura de pesquisa (Gil, 1999; Strauss e Corbin, 2008), mormente na área de pesquisa qualitativa (Denzin e Lincoln, 2000). Dessa forma, na etapa de construção do esquema estrutural, foram utilizadas pesquisa bibliográfica e documental, a técnica Delphi e entrevistas em profundidade com especialistas. Nessa etapa fundamentalmente exploratória, as fontes para a busca na literatura foram as revistas Ideia Social, Brasil Responsável e journals como Journal of Public Policy and Marketing, Journal of Social Issues e Social Marketing Quarterly.

Após essa fase, o procedimento Delphi foi conduzido com uma rodada inicial de 25 acadêmicos - identificados a partir de produção acadêmica na área, em eventos como Anpad, EMA e periódicos - e 210 profissionais, identificados como planejadores/coordenadores de programas de marketing social a partir de listas de discussões, organogramas de instituições, palestrantes ou com trabalho aceito em eventos na área - tais como a Mostra Nacional de Experiências Bem-Sucedidas em Epidemiologia, Prevenção e Controle de Doenças, organizada anualmente pelo Ministério da Saúde —, artigos na mídia e recomendação pessoal.

A coleta de dados foi feita por meio de um questionário semiestruturado, assegurando o anonimato às respostas e em rodadas sucessivas. A primeira rodada desta pesquisa foi com uma mensagem eletrônica inicial, pessoal e individualizada, preparatória aos participantes, e envio na semana seguinte do questionário da primeira rodada com os seguintes tópicos, tendo por base a revisão de literatura, análise documental e estudo anterior (Meira e Slongo, 2008), que tratava especificamente da avaliação de campanhas de segurança no trânsito. No questionário, apresentou-se novamente o estudo, com objetivos e método, verificaram-se, na opinião do entrevistado, quais as possíveis dimensões para se avaliar o desempenho de programas de marketing social, quais indicadores poderiam compor essas dimensões, de que forma esses indicadores poderiam ser medidos, quando deveria ser realizada essa avaliação dos indicadores, perfil do respondente (classificação e nível de escolaridade) e agradecimento final.

Após sumarização dos resultados da pesquisa, o conteúdo foi submetido a um juiz, para verificação da pertinência da análise, com ajustes de consenso na última parte do texto. Um segundo e-mail foi enviado com o novo link da pesquisa. Em função da convergência das respostas, e taxa de abandono - como previsto em Hair e colaboradores (2005) e Vergara (2008) — , deu-se por encerrada a Delphi após a segunda rodada. Para a análise dos dados, foi usada a técnica de análise de conteúdo, com grade fechada, para verificar-se a eventual convergência das respostas.

Os resultados da Delphi foram discutidos por entrevistas em profundidade com novos especialistas selecionados, pelo uso da chamada "entrevista centralizada no problema", sugerida por Witzel (apud Flick, 2004:100-102), na qual há a orientação do pesquisador 
para um problema social relevante. Foram três os grupos de entrevistados nessa etapa: (a) acadêmicos, selecionados a partir de produção publicada na área de marketing social, em periódicos e anais de eventos científicos, que poderiam ter contribuições teóricas relevantes com relação à avaliação de desempenho de programas de marketing social; (b) profissionais de marketing social, identificados a partir da investigação, na mídia e em documentos, de cargo ou função de planejadores e/ou coordenadores de programas de marketing social, em diferentes âmbitos (municipal, estadual, nacional) e temáticas empreendidas; e (c) intermediários, tais como voluntários engajados em programas de marketing social, que poderiam aportar insights importantes a respeito das dificuldades cotidianas de avaliação de programas na área.

Utilizou-se guias de entrevista (daí serem semiestruturadas, ou dirigidas), para evitar que a entrevista "não se perca em tópicos sem relevância" (Flick, 2004:104). Definiu-se para esta etapa a realização de entrevistas com pelo menos cinco representantes de cada grupo, tendo havido oportunidade, ao final, de um total de 20 entrevistas em profundidade.

Como tratamento das entrevistas, foi realizada análise de conteúdo, com base em Bardin (1977) e Vergara (2008).

Para o exame de adequação e da aplicabilidade da estrutura conceitual desenvolvida, foi agregado a este trabalho o método de estudo de caso, em duas diferentes instituições e programas. O uso de múltiplos métodos é uma tentativa de favorecer uma compreensão mais aprofundada do fenômeno investigado em comparação ao uso de um único método (Denzin e Lincoln, 2006:19), e o processo de variar técnicas e métodos de coleta pode ser chamado de triangulação (Strauss e Corbin, 2008:55). Essa triangulação não é exatamente uma estratégia de validação, mas uma alternativa à validação, em uma estratégia que pode acrescentar rigor, complexidade e riqueza a uma investigação (Flick, 2004:237).

De forma a perseguir-se confiabilidade no estudo de caso, minimizando os erros e tendenciosidades, elaborou-se um protocolo do estudo de caso, seguindo recomendação de Yin (2001:60). Executou-se o estudo de dois casos de programas de marketing social, com base nos seguintes critérios: local $\times$ regional, temporalidade, natureza e relevância do programa:

a) Empresa Pública de Transporte e Circulação (EPTC). Há um quadro grave de vítimas fatais (50 mil por ano no Brasil; 1.600, no Rio Grande do Sul) e não fatais no trânsito brasileiro (estimadas em 450 mil por ano, pelo Departamento Nacional de Trânsito — Denatran), que, em Porto Alegre, a EPTC, ligada à Prefeitura Municipal de Porto Alegre, buscou enfrentar pelo "Programa Novo Sinal".

b) Centro Estadual de Vigilância em Saúde (RS). Órgão da Secretaria Estadual da Saúde, do Governo do Estado do Rio Grande do Sul, cujos programas abordados foram o Enfrentamento às Hepatites Virais — estima-se que cerca de 200 mil gaúchos estejam, alguns sem sequer sabê-lo, infectados com um dos três tipos mais comuns da doença no estado, a saber, Hepatite A, B ou C — e a Vacinação para a Gripe A — vírus H1N1. 
Figura 4

Outdoor com aplique da Campanha Novo Sinal

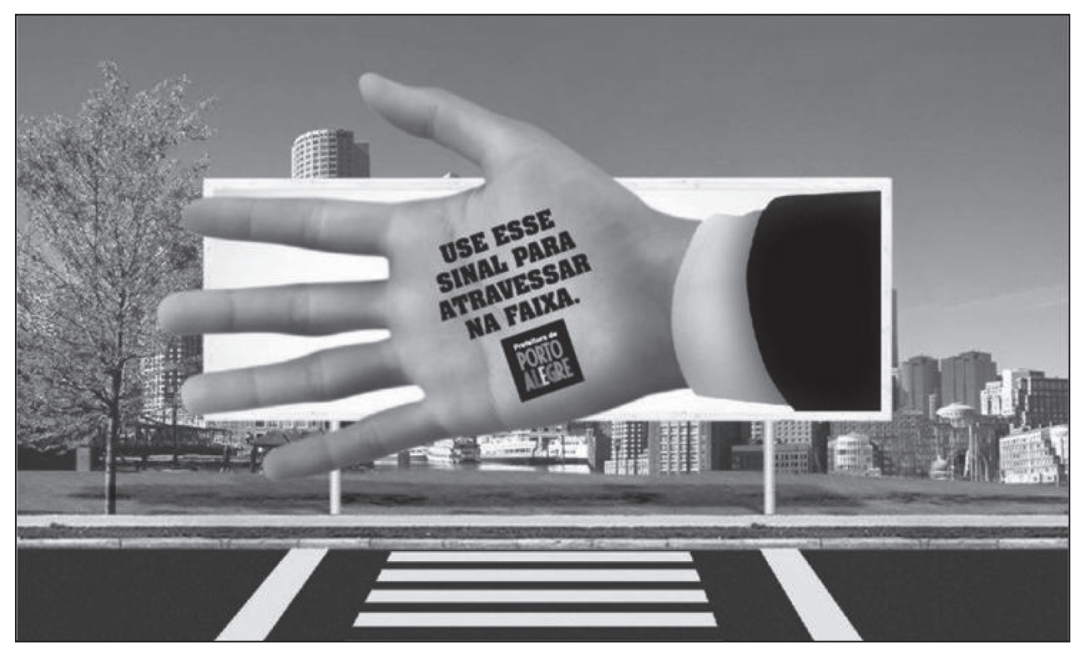

Fonte: cortesia Paim Comunicação.

Figura 5

Volante informativo para jovens sobre as hepatites virais

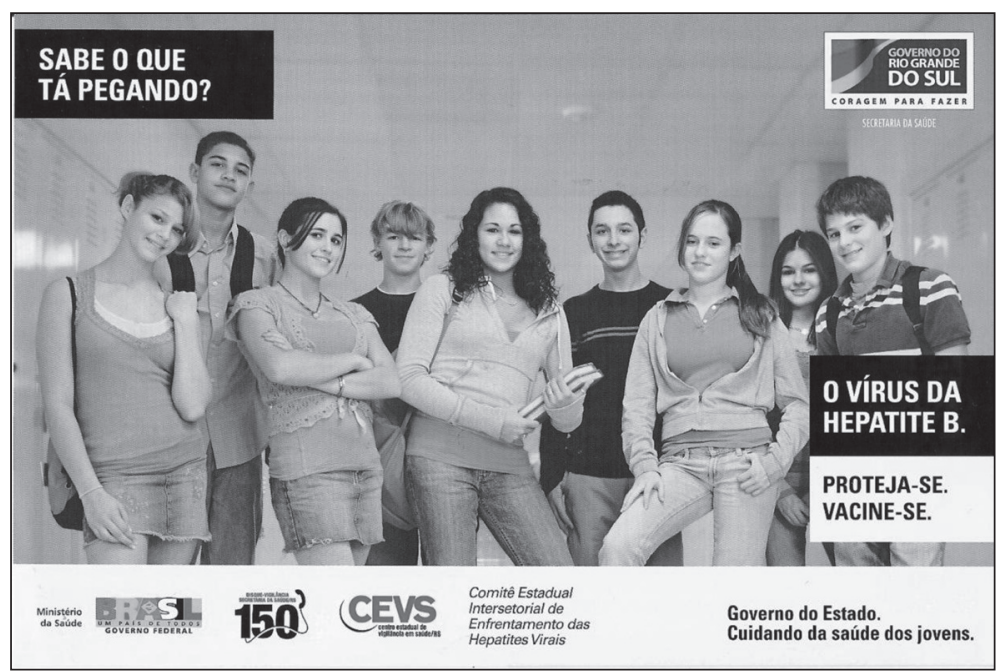

Fonte: Comitê de Ação Solidária.

Os informantes-chave dos estudos de caso foram de três instâncias: (1) planejadores/ coordenadores dos programas de marketing social, (2) criadores da campanha em termos de comunicação publicitária e (3) executores dos programas. 
A coleta de dados consistiu de observação direta, entrevistas em profundidade com roteiro semiestruturado com os informantes-chave de cada caso e levantamento documental com base em material de imprensa, websites de informação ou corporativos, material de campanha e relatórios de trabalho.

A análise dos estudos de caso foi feita por análise documental (Gil, 1999; Yin, 2001) e análise de conteúdo das entrevistas (Bardin, 1977; Flick, 2004; Vergara, 2008). Em estudos de casos, "o uso mais importante de documentos é corroborar e valorizar as evidências oriundas de outras fontes" (Yin, 2001:109). Houve uma pré-análise do material, com leitura flutuante e escolha dos documentos, formulação dos objetivos, preparação do material, sua exploração e tratamento dos resultados e interpretação, conforme preconizado por Bardin (1977:95-102).

\section{Análise dos resultados}

Na pesquisa Delphi, dos 240 nomes listados, houve retorno por parte de 39 respondentes - dos quais, nove acadêmicos — na primeira rodada do método. As respostas foram organizadas por meio de um ordenamento conceitual. ${ }^{2}$ Na segunda rodada da pesquisa Delphi, um resumo dessas respostas foi enviado à amostra inicial. Conforme previsto por Hair e colaboradores (2005) e Vergara (2008), houve algumas desistências entre os respondentes da primeira rodada, tendo retornado respostas de 26 participantes. Isso se deu na terceira semana de novembro de 2009. Os respondentes se manifestaram sobre (a) o que se deveria medir em programas de marketing social, (b) que indicadores poderiam ser usados, (c) de que forma se deveria fazer a avaliação dos indicadores [novo item em relação à anterior], e (d) em que momento do programa de marketing se deveria realizar essa avaliação. A análise inicial foi validada pelo mesmo segundo examinador (juiz) da primeira rodada, havendo três ajustes, após discussão e consenso.

Agruparam-se os resultados no quadro 1 a seguir, com a distinção de avaliação de produção, resultados e impacto de Kotler e Lee (2008), tais como apareceram na pesquisa, mas que sofreram ordenamento conceitual após a etapa seguinte das entrevistas em profundidade, para organização da estrutura conceitual desta investigação.

Algumas observações, como "avaliação formativa de processo" e "efetividade nos resultados", estão, assim, genéricas, por terem sido manifestações textuais dos respondentes (códigos in vivo), mas estão retrabalhadas na estrutura conceitual a seguir no artigo.

\footnotetext{
${ }^{2}$ Chama-se de ordenamento conceitual a organização (e algumas vezes classificação) de dados segundo um conjunto seletivo e específico de propriedades e de suas dimensões (Strauss e Corbin, 2008:29).
} 
Resultados após segunda rodada Delphi

\begin{tabular}{|c|c|c|c|}
\hline Dimensões de avaliação & Indicadores & $\begin{array}{l}\text { Formas de avaliarem-se } \\
\text { os indicadores }\end{array}$ & $\begin{array}{l}\text { Momento da avaliação } \\
\text { (geral) }\end{array}$ \\
\hline $\begin{array}{l}\text { Produção: } \\
\text { v Estudo inicial de motivações do } \\
\text { público-alvo, por pesquisa-ação } \\
\text { de compreensão prévia dos } \\
\text { indivíduos } \\
\text { v Qualidade das ações } \\
\text { v Envolvimento, } \\
\text { comprometimento e aderência } \\
\text { da equipe } \\
\text { vesquisa-ação, com } \\
\text { entendimento prévio do público } \\
\text { v Análise de processo do } \\
\text { programa, nas várias etapas } \\
\text { v Custos financeiros da ação } \\
\text { v Implementação efetiva da } \\
\text { campanha }\end{array}$ & 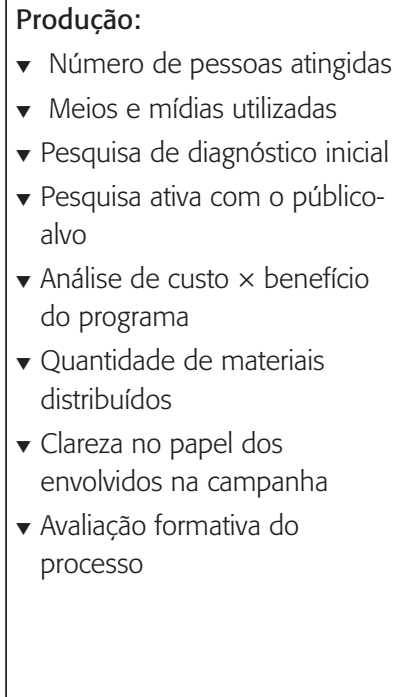 & 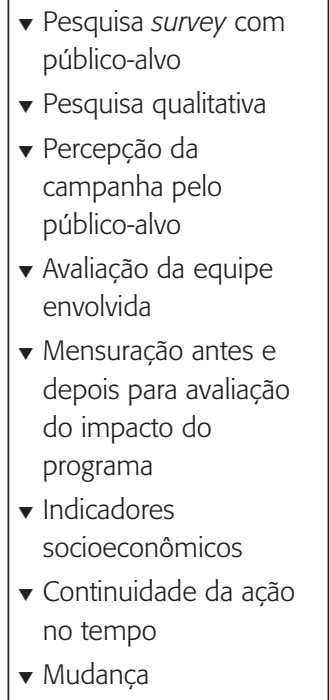 & $\begin{array}{l}\text { v Em três momentos: } \\
\text { antes, durante e depois } \\
\text { v Permanentemente } \\
\text { v Antes e depois } \\
\text { v Durante (avaliação } \\
\text { formativa) e depois } \\
\text { v Durante o processo } \\
\text { (avaliação formativa) } \\
\text { v Após a ação }\end{array}$ \\
\hline 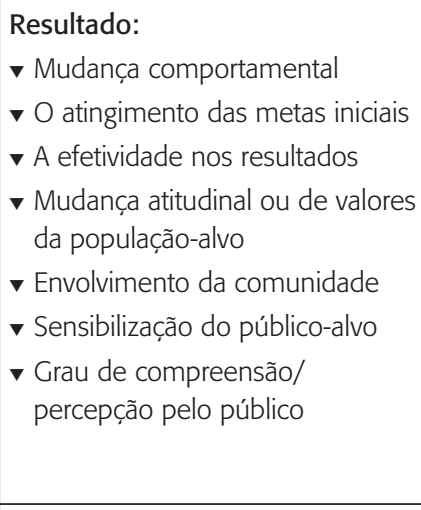 & $\begin{array}{l}\text { Resultado: } \\
\text { - Mudança comportamental e } \\
\text { seus impactos } \\
\text { - Percepção e recall da } \\
\text { campanha pelo público-alvo } \\
\text { - Satisfação geral dos } \\
\text { participantes } \\
\text { - Conduta ética do indivíduo } \\
\text { - Pesquisa por observação } \\
\text { - Nível de conhecimento, } \\
\text { valores e crenças do público- } \\
\text { alvo sobre o tema }\end{array}$ & 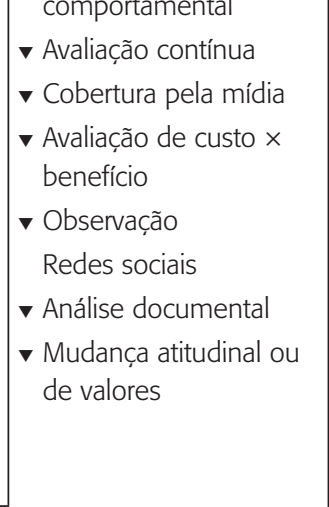 & \\
\hline $\begin{array}{l}\text { Impacto: } \\
\text { v Abrangência e disseminação } \\
\text { [repercussão] da campanha } \\
\text { v Impacto da campanha } \\
\text { v Qualidade de vida da população } \\
\text { v Satisfação do público-alvo } \\
\text { v Influência do grupo social sobre } \\
\text { o indivíduo }\end{array}$ & 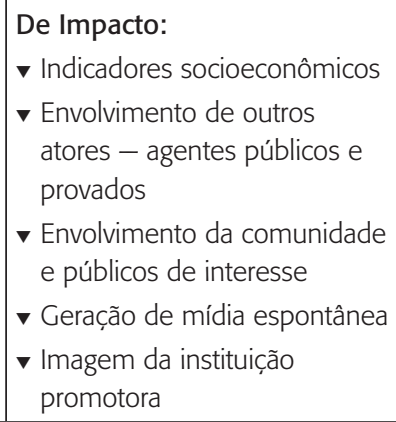 & & \\
\hline
\end{tabular}

Fonte: elaborado pelos autores. 
Percebeu-se, nas manifestações abertas da pesquisa, grande valor dado ao input, ou seja, todo o levantamento inicial prévio ao processo em si. Esta foi, por esse motivo, uma dimensão que seria avaliada nas entrevistas em profundidade. Uma dimensão da literatura que apareceu citada, mas sem maior consistência, foi a de ética, que foi então aprofundada, para melhor compreensão, na etapa de entrevistas em profundidade.

A etapa de entrevistas em profundidade com os especialistas se deu nos meses de dezembro e janeiro de 2010, envolvendo, ao final, 20 entrevistados, divididos em três categorias: acadêmicos, executivos/consultores e voluntários de programas sociais, tendo sido aprofundadas as questões de (a) o que se deve avaliar em programas de marketing social, (b) quais as principais dificuldades encontradas nas avaliações dos programas, (c) uma análise acerca das principais dimensões de avaliação trazidas pela literatura (tais como no quadro 2).

\section{Quadro 2}

\section{Principais dimensões de avaliação em marketing social conforme a literatura}

\begin{tabular}{|lll|}
\hline Dimensão & \multicolumn{1}{c|}{ Descrição } & \multicolumn{1}{c|}{ Fonte } \\
\hline Impacto & Efeitos de longo prazo e consequências do programa & Weinreich (1999) \\
& & $\begin{array}{l}\text { Kotler e Roberto (1992) } \\
\text { Kotler e Lee (2008) }\end{array}$ \\
& & Técnica Delphi \\
Ética & Aspectos éticos com relação a público-alvo, métodos ou & Kotler e Roberto (1992) \\
& consequências do programa & Técnica Delphi \\
Resultados & Respostas dadas pelo público-alvo do programa & Weinreich (1999) \\
& & Kotler, Roberto e Lee (2002) \\
& & Gill, Flynn e Reissing (2005) \\
& & Kotler e Lee (2008) \\
Processo/produção & Técnica Delphi \\
& Esforço e competência da entidade durante a realização & Kotler, Roberto e Lee (2002) \\
& do programa & Gill, Flynn e Reissing (2005) \\
& & Kotler e Lee (2008) \\
Input & Técnica Delphi \\
& Qualidade das informações prévias e planejamento & Gill, Flynn e Reissing (2005) \\
& inicial do programa & Técnica Delphi \\
\hline
\end{tabular}

Fonte: organizado pelos autores.

A contribuição dada pelos entrevistados permitiu um maior entendimento das manifestações emergidas nas rodadas Delphi. Neste momento, passa-se à estrutura conceitual pretendida, que somou as contribuições da literatura aos dados primários coletados na primeira fase da pesquisa. 


\subsection{Proposição da estrutura conceitual de avaliação}

Apresenta-se, a seguir, a estrutura conceitual proposta nesta investigação. Sua categoria central, ou categoria básica, que "representa o tema principal da pesquisa" (Strauss e Corbin, 2008:145), é “avaliação de programas de marketing social”. A estrutura apresentada no quadro 3 está dividida nas categorias de Input, Processo e Resultado, e correspondem, respectivamente, às fases de avaliação de diagnóstico inicial, avaliação formativa e avaliação somativa. Essas categorias estão, por sua vez, divididas em subcategorias, que, conforme Strauss e Corbin (2008:103), são "conceitos que pertencem à categoria, dando esclarecimentos e especificações adicionais". A cada subcategoria — que também podemos denominar de "variável" —, estão relacionados indicadores e formas de mensuração possível.

A divisão inicial de três momentos foi fortemente manifestada na pesquisa Delphi, e em diversas passagens da literatura, levando ao entendimento de que um processo completo de avaliação deve fazer um diagnóstico inicial da situação (até mesmo para levar-se adiante ou abortar-se o próprio programa de marketing social), realizar-se uma avaliação formativa - defendida com entusiasmo tanto na Delphi quanto nas entrevistas em profundidade, e uma avaliação somativa, final, que é o modo tradicional de avaliação.

Ao longo das entrevistas em profundidade, tornou-se mais claro que, em vez das cinco dimensões mais comuns da literatura - Input, Processo, Impacto, Resultado e Ética —, poderiam restar três grandes dimensões, que comporiam as categorias principais do processo, uma vez que "Impacto" é, como reiteradamente surgiu na pesquisa, uma forma de "Resultado", ou seja, poderia ser por este englobado, sem necessidade de ser tratada como uma categoria à parte. Por sua vez, a dimensão de "Ética" ficaria sem sentido se isolada como uma das categorias de avaliação, pois ficou evidenciado em Kotler e Roberto (1992), Duke e colaboradores (1993), Kotler, Roberto e Lee (2002), Andreasen (2003) e Furrow (2007) e na etapa de entrevistas em profundidade, que a Ética perpassa - idealmente - as demais dimensões, transversalmente. Como resumiu um dos entrevistados, "ética é imprescindível em todas as dimensões". Dessa forma, ela foi diluída como uma das variáveis de avaliação em cada uma das três categorias principais. Essa pluralidade de aspectos tende a diminuir a falta de clareza, reportada na literatura, acerca de quais informações são efetivamente utilizadas em avaliação, no cotidiano profissional (Kundin, 2010).

Igualmente, a dimensão de Input é a categoria natural da fase de diagnóstico; a dimensão de Processo é a essência de uma avaliação formativa; e a dimensão de Resultados é a que compete a uma etapa final, de avaliação somativa, como preconizado no referencial teórico desta investigação. 


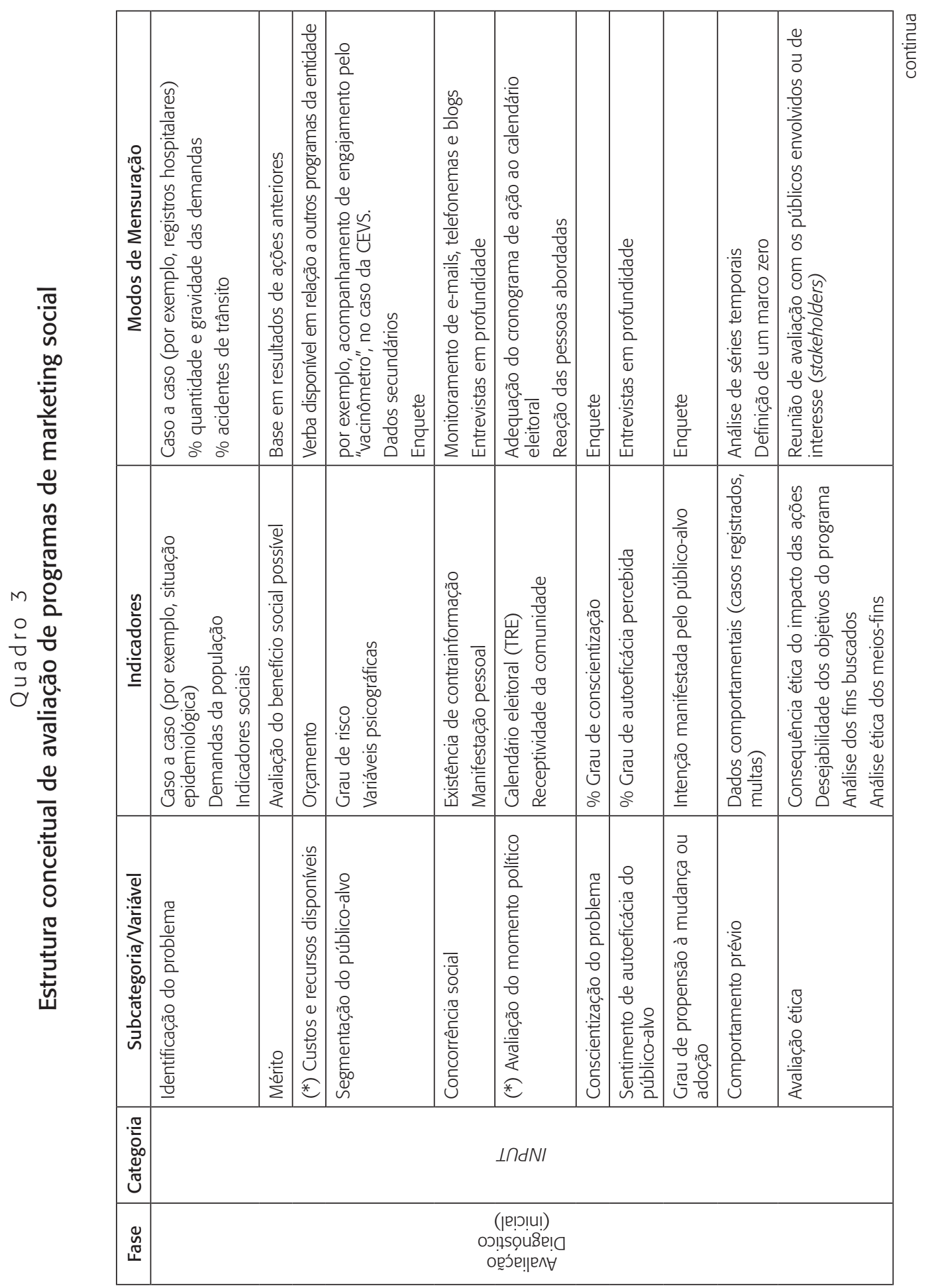

RAP - Rio de Janeiro 46(2):493-522, mar./abr. 2012 


\begin{tabular}{|c|c|c|c|c|c|c|c|c|c|c|c|c|c|c|c|}
\hline 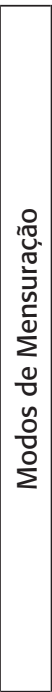 & 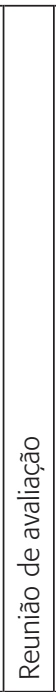 & 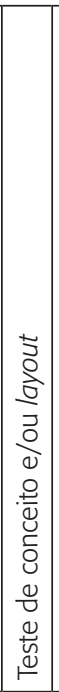 & 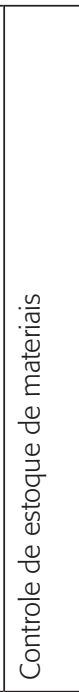 & 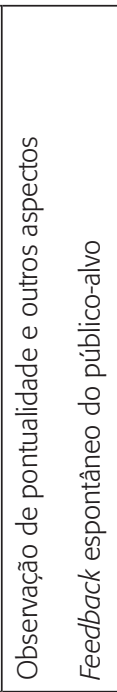 & 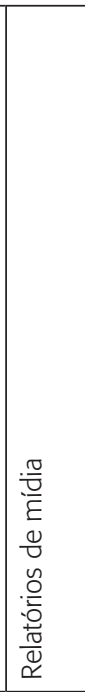 & 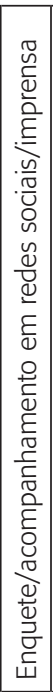 & 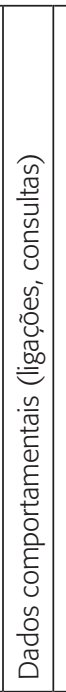 & 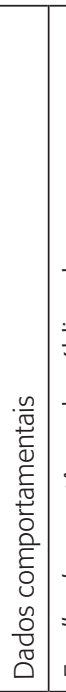 & 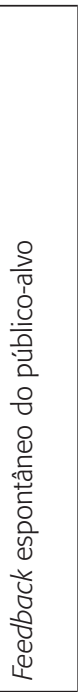 & 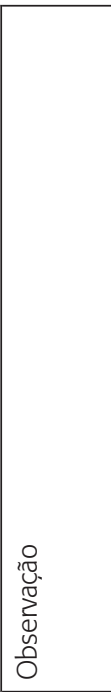 & & 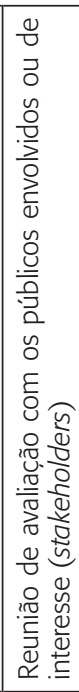 & 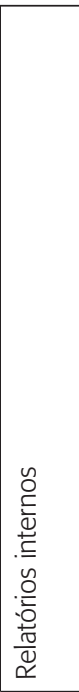 & 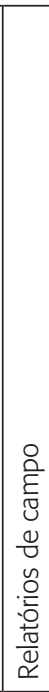 & 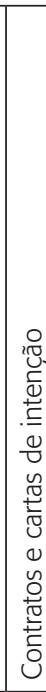 \\
\hline 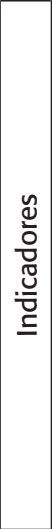 & 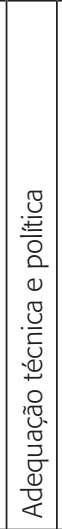 & 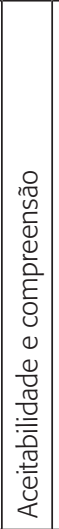 & 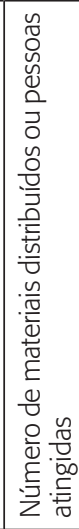 & 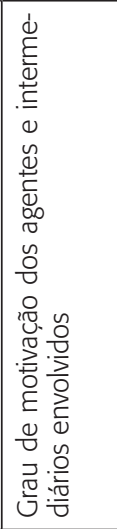 & 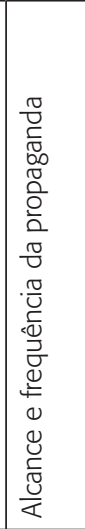 & 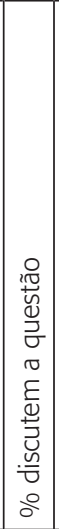 & 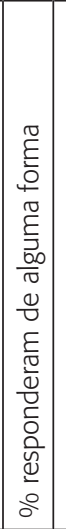 & 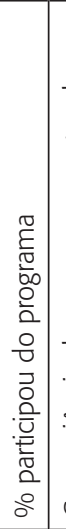 & 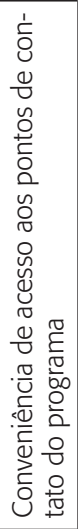 & 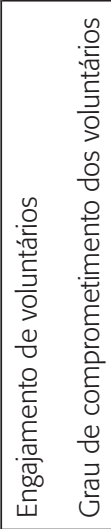 & 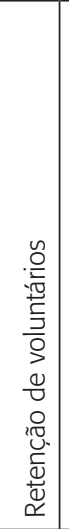 & 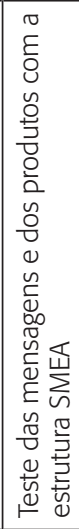 & 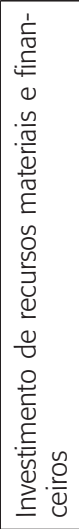 & 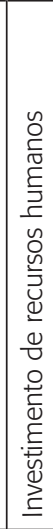 & 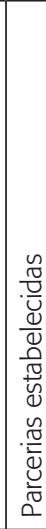 \\
\hline 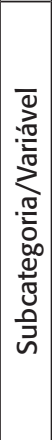 & 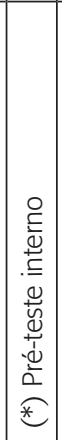 & 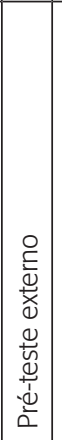 & 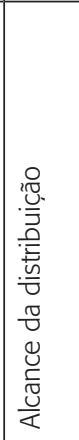 & 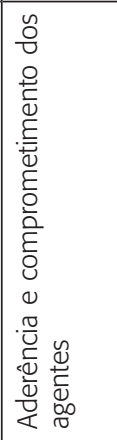 & 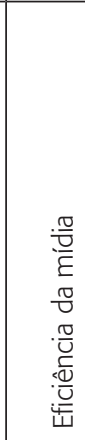 & 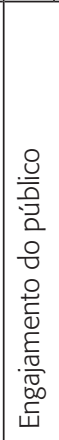 & & & 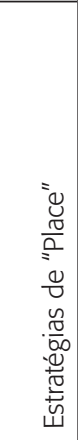 & 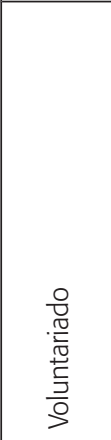 & & 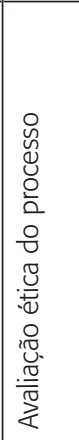 & 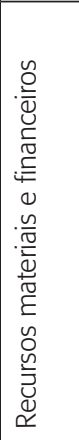 & 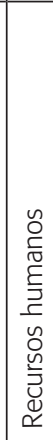 & 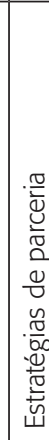 \\
\hline 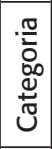 & \multicolumn{15}{|c|}{ OSSヨכOYd } \\
\hline 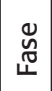 & \multicolumn{15}{|c|}{ 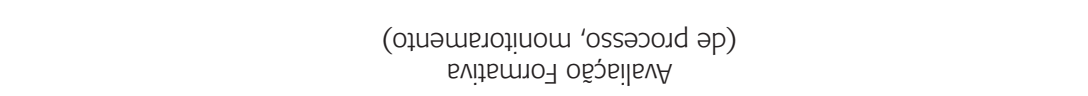 } \\
\hline
\end{tabular}

RAP - Rio de Janeiro 46(2):493-522, mar./abr. 2012 


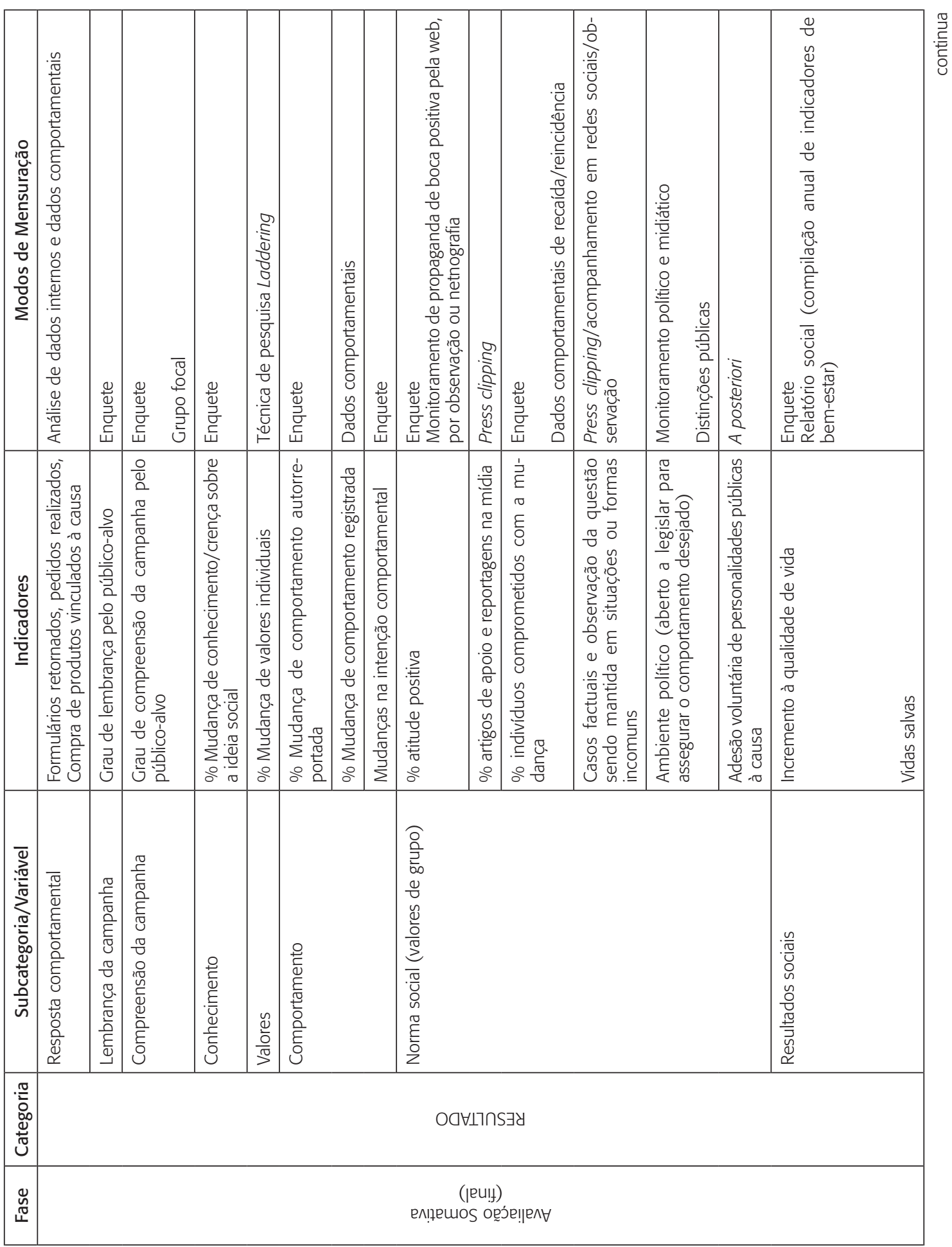

RAP - Rio de Janeiro 46(2):493-522, mar./abr. 2012 

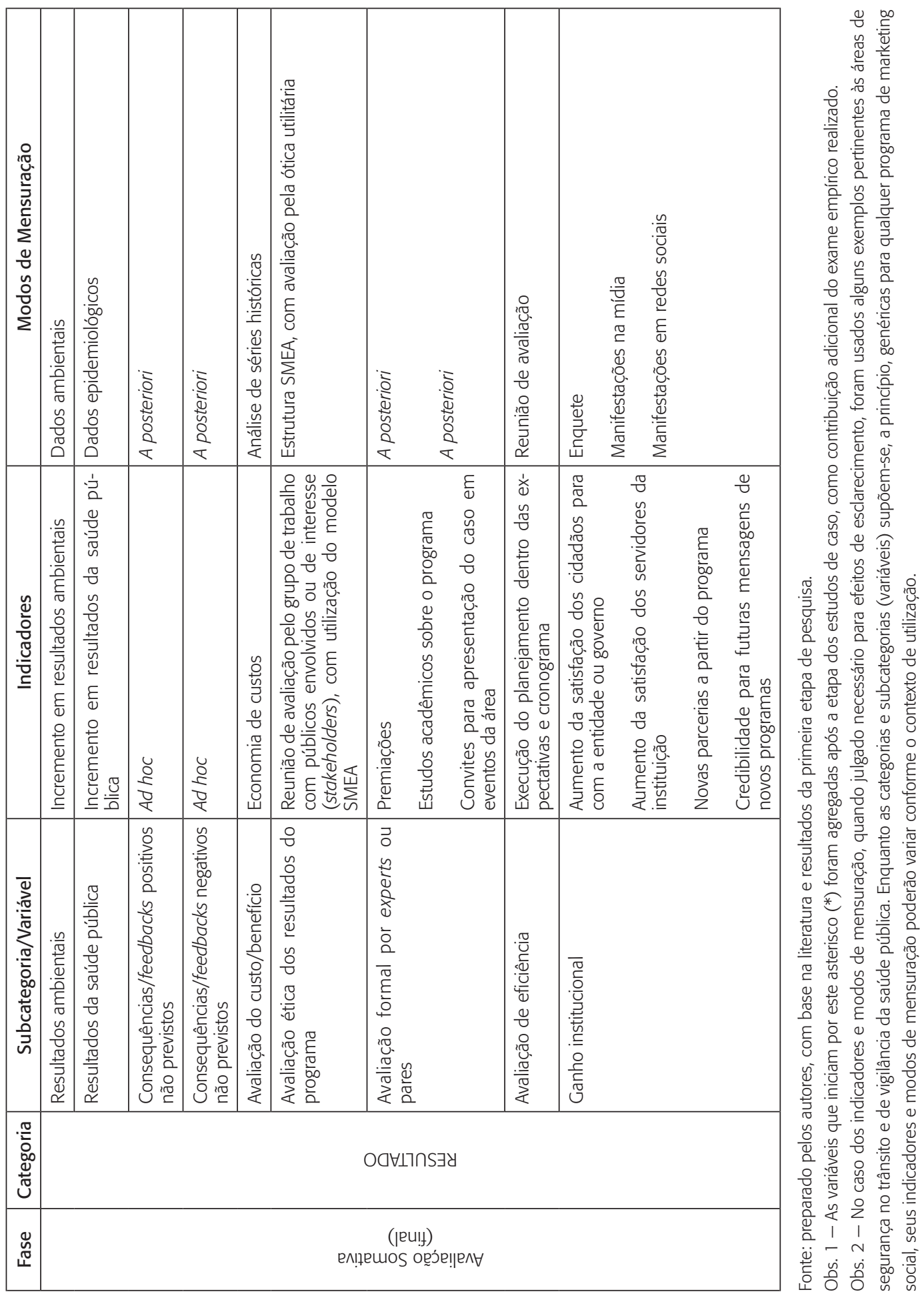

RAP - Rio de Janeiro 46(2):493-522, mar./abr. 2012 
Um detalhamento dos termos e conceitos usados nas categorias e subcategorias no quadro 3 favorecerá seu entendimento e utilização:

INPUT: Categoria de análise própria de uma avaliação de diagnóstico, na qual se colhem os subsídios para o programa.

v Identificação do problema: ao qual possa responder-se com uma "oferta" social.

v Mérito: validade ou relevância do programa visando combate ao problema identificado.

、 Análise de custos e recursos disponíveis: o programa pode não ser viável em um determinado momento.

、 Segmentação do público-alvo: pode ser feito pela necessidade da ação, ou pelo perfil psicográfico (demográfico e estilo de vida).

v Concorrência social: Avaliação de comportamento concorrente, ou de informações contrárias à desejada.

、 Avaliação do momento político: em determinados períodos, se próximo a eleições, campanhas podem ser mal interpretadas.

Conscientização do problema

v Sentimento de autoeficácia do público-alvo: o público-alvo deve acreditar que é capaz de mudar conforme a proposição desejada.

v Grau de propensão à mudança ou adoção: atitude mais ou menos inclinada à ideia social.

v Comportamento prévio: para que se tenha um "marco zero" de avaliação posterior.

v Avaliação ética do planejamento do programa: com discussão dos possíveis impactos e consequências, envolvendo grupo multidisciplinar.

PROCESSO: É o momento da avaliação formativa, a qual permite que correções necessárias sejam feitas para um melhor desempenho do programa.

จ Pré-teste interno do material: é testada a adequação técnica e mesmo política do material, na instituição.

v Pré-teste externo do material: são testados o conceito e layout do material junto ao público-alvo.

\ Alcance da distribuição: área ou pessoas atingidas.

v Aderência e comprometimento dos agentes: o agente social e os intermediários precisam acreditar na campanha.

จ Eficiência da mídia: em termos de cobertura ou atingimento do público-alvo, e adequação ao perfil do público. 
、 Engajamento do público: grau em que está havendo adoção do público, durante o processo.

v Estratégias de "Place": verificação se os pontos de distribuição e contato da campanha estão sendo convenientes ao público-alvo.

v Voluntariado: em caso de haver, avaliação de seu engajamento à causa e mesmo retenção no programa.

、 Avaliação ética do processo: avalia-se, à luz da ética, como estão sendo as respostas do público ao programa; utilização da estrutura conceitual SMEA (Avaliação Ética de Marketing Social, de Kirby e Andreasen, 2001).

、 Recursos materiais e financeiros: quanto está sendo investido nesses recursos.

V Recursos humanos: quantas pessoas colocadas à disposição, e por quanto tempo?

、 Estratégias de parceria: se está se somando esforços com outra entidade com a mesma causa e objetivos afins.

RESULTADO: Momento em que se realiza a avaliação somativa, ao final do processo, e no qual se têm as consequências imediatas e impactos de longo prazo do programa.

v Resposta comportamental: aos elementos da campanha.

、 Lembrança da campanha: recall por parte do público.

、 Compreensão da campanha: extensão em que a mensagem foi compreendida.

\ Conhecimento: novos conhecimentos ou crenças a respeito da ideia social.

v Valores: avaliação da eventual mudança de valores do indivíduo.

จ Comportamento: do público-alvo em face dos objetivos do programa.

จ Norma social: até que ponto os novos valores foram incorporados culturalmente pela sociedade.

V Resultados sociais: tais como incremento em qualidade de vida.

V Resultados ambientais: quando for o caso de campanhas ligadas ao meio ambiente.

、 Resultados da saúde pública: impactos de longo prazo na saúde da comunidade.

、 Consequências/feedbacks positivos (não previstos): tais como cartas, artigos na mídia, e-mails de reforço.

v Consequências/feedbacks negativos (não previstos): tais como cartas, artigos na mídia, e-mails de crítica. 
V Avaliação do custo/benefício: em caráter definitivo, comparado com o inicialmente previsto.

、 Avaliação ética dos resultados: análise de possíveis consequências negativas não previstas.

- Avaliação formal por experts ou pares: por exemplo, premiações, convites para compartilhamento da experiência com outros.

v Avaliação de eficiência: Até que ponto o cronograma foi seguido e objetivos atingidos em relação às expectativas.

- Ganho institucional: consequências positivas para a própria instituição que promoveu o programa social, e que podem gerar benefícios para programas futuros.

A estrutura foi examinada à luz de dois casos de programas de marketing social (que visam à mudança social planejada) — segurança no trânsito e saúde pública - e a lógica das categorias e respectivas variáveis foi discutida com informantes-chave desses casos, tendo os indicadores e formas de mensuração sido desenvolvidos pelos pesquisadores após as entrevistas dos estudos de caso, tendo por base a literatura e etapas anteriores deste trabalho.

\subsection{Análise da estrutura proposta}

Para validação de face da estrutura proposta, realizaram-se os estudos de caso da Empresa Pública de Transporte e Circulação e do Centro Estadual de Vigilância em Saúde (RS), com análise de material de campanha, documentos e relatórios, e entrevistas com os principais envolvidos no programa.

$\mathrm{Na}$ avaliação do esquema estrutural junto aos estudos de caso, foram levados em conta os critérios de avaliação de esquemas de classificação defendidos por Hunt (2002) e utilizada conjuntamente, para a avaliação do esquema conceitual, a proposição de Rossiter (2001:21) de que esquemas estruturais devem ser avaliados "por sua completude, clareza e aplicabilidade".

No caso do "Novo Sinal de Trânsito", as contribuições da análise foram: (a) integração, à estrutura conceitual, da variável "avaliação externa por experts ou pares", uma vez que o programa recebeu premiações do mercado publicitário, em eventos reconhecidos, o que não deixa de ser outra forma de avaliação da competência de sua execução; (b) maior precisão na denominação da variável "avaliação da concorrência"; (c) inclusão da variável "avaliação do momento político", na categoria "Input"; (d) sugestão de inclusão da variável "análise de custos e recursos disponíveis", em função do processo de "engessamento" que o orçamento de um órgão público possa ter; (e) sugestão da divisão da variável "pré-teste do material", na categoria de Processo, em duas fases: um pré-teste interno e outro externo e (f) renomeação da variável "Crença". Um sentimento geral dos respondentes foi o de receber com satisfação, 
na estrutura conceitual, uma proposta de avaliação que não baseava a avaliação de uma campanha de educação para o trânsito tão somente nos índices de mortalidade, uma vez que há várias causas que interferem nesses índices.

No que tange ao Cevs/RS, a estrutura conceitual apresentada pelo pesquisador foi avaliada como adequada pelas entrevistadas do Comitê de Ação Solidária e do Cesv/RS que, não obstante, fizeram as seguintes observações, já incorporadas, conforme sua natureza, na estrutura do quadro 3: (a) na variável de "Identificação do problema", no caso específico do Cevs/RS, um dos indicadores poderia ser a "situação epidemiológica"; (b) readequação de denominação de variáveis e (c) reordenamento das variáveis na estrutura proposta; validaram diversas variáveis com exemplos concretos de sua área de atuação.

Na seção seguinte, passa-se à discussão dos resultados obtidos neste trabalho, a partir dos métodos de pesquisa utilizados e da análise dos dados realizada.

\section{Discussão dos resultados}

A literatura de marketing social traz diferentes estruturas conceituais acerca de quais categorias de análise seriam as mais importantes, concentrando-se, em um apanhado geral das proposições, nas categorias de Input, Processo, Resultados, Impacto e Ética. À medida que este trabalho ia sendo executado, foi fazendo sentido ao pesquisador condensá-las nas realmente mais importantes, em um número menor - mais "administrável”, conforme um dos respondentes, e mais facilmente lembrado, segundo Rossiter (2001) —, evoluindo qualitativamente das estruturas conceituais apresentadas tanto em livros-texto (Kotler e Roberto, 1992; Weinreich, 1999; Kotler, Roberto e Lee, 2002; Kotler e Lee, 2008) quanto em artigos acadêmicos (Doner, 2003; Varcoe, 2004).

Com apoio na pesquisa Delphi, nas entrevistas em profundidade e na literatura, passou-se a pensar-se em três momentos de avaliação — antes, durante e depois — às quais correspondiam naturalmente três das categorias do grupo maior, a saber, Input, Processo e Resultado, como haviam sido tratadas em Gill, Flynne Reissing (2005), mas aqui examinadas empiricamente no contexto de marketing social. A dimensão de "Impacto" foi absorvida sem resistência pela categoria "Resultados" (e era mesmo um sinônimo para diversos autores e entrevistados), e a dimensão de Ética terminou compreendida como uma variável presente em todas as fases do processo. Ainda que mais crítica seja a reflexão ética no planejamento inicial de um programa de marketing social, sua importância foi manifestada na execução do programa e na avaliação final do impacto que o programa teve sobre a sociedade. Como disse um dos entrevistados, "se trabalhamos com pessoas, não há como não pensar em ética, ao fazê-lo". Assim, ela foi absorvida como uma das variáveis de avaliação em cada uma das três categorias principais. 


\section{Quadro 4}

\section{Estrutura conceitual de avaliação genérica de programas de marketing social}

\begin{tabular}{|c|c|c|}
\hline Fase & Categoria & Subcategoria/Variável \\
\hline 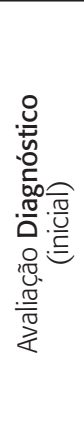 & $\stackrel{5}{\vdots}$ & 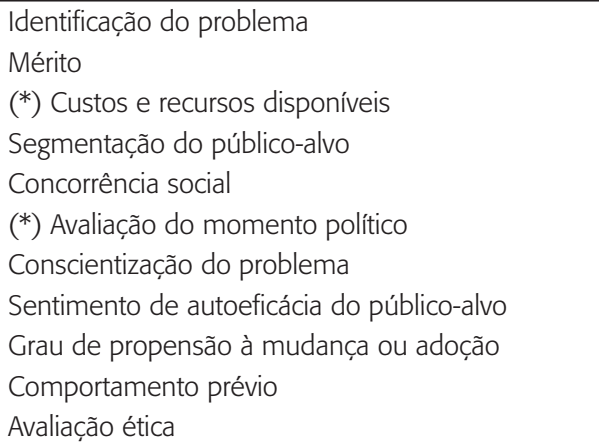 \\
\hline 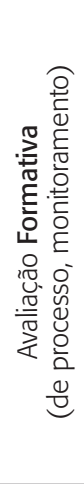 & 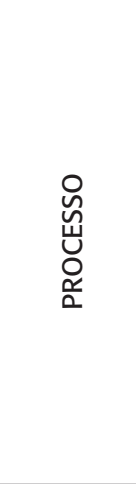 & $\begin{array}{l}\text { (*) Pré-teste interno } \\
\text { Pré-teste externo } \\
\text { Alcance da distribuição } \\
\text { Aderência e comprometimento dos agentes } \\
\text { Eficiência da mídia } \\
\text { Engajamento do público } \\
\text { Estratégias de "Place" } \\
\text { Voluntariado } \\
\text { Avaliação ética do processo } \\
\text { Recursos materiais e financeiros } \\
\text { Recursos humanos } \\
\text { Estratégias de parceria }\end{array}$ \\
\hline 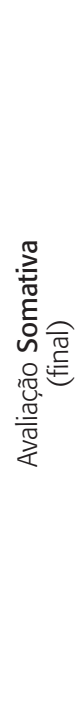 & 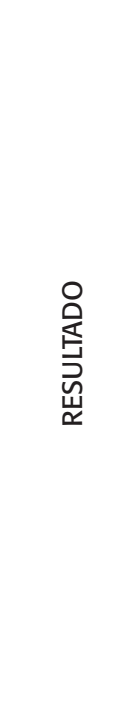 & $\begin{array}{l}\text { Resposta comportamental } \\
\text { Lembrança da campanha } \\
\text { Compreensão da campanha } \\
\text { Conhecimento } \\
\text { Valores } \\
\text { Comportamento } \\
\text { Norma social (valores de grupo) } \\
\text { Resultados sociais } \\
\text { Resultados ambientais } \\
\text { Resultados da saúde pública } \\
\text { Consequências/feedbacks positivos não previstos } \\
\text { Consequências/feedbacks negativos não previstos } \\
\text { Avaliação do custo/benefício } \\
\text { Avaliação ética dos resultados do programa } \\
\text { Avaliação formal por experts ou pares } \\
\text { Avaliação de eficiência } \\
\text { Ganho institucional }\end{array}$ \\
\hline
\end{tabular}

Fonte: preparado pelos autores. 
Na estrutura conceitual proposta, as categorias de avaliação e suas variáveis pretendem ser genéricas, conforme o quadro 4, aplicáveis em diferentes programas de marketing social. Entretanto, seus indicadores ou suas formas de mensuração podem necessitar de adaptações, conforme o contexto de aplicação. Dessa forma, estudos futuros poderiam ser feitos em áreas específicas, para que a estrutura abarcasse os indicadores e formas de avaliação ideais para cada área e se tornasse um instrumento mais sólido para uso nessa especificidade. Por exemplo, para o caso de um programa de combate à violência doméstica, sejam desenvolvidos indicadores, e forma de mensurá-los, que sejam idealmente os apropriados para a questão em pauta. Dessarte, como demonstrado nas limitações do trabalho, a questão de avaliação ética, não obstante manifestada como essencial pelos participantes do estudo na etapa de entrevistas em profundidade, ainda carece de uma investigação que permita que oriente a ação prática das instituições públicas. Linhas gerais, ou diretrizes, existem, mas a área carece de um instrumento, ou ferramental, de aplicação para análise em situações concretas de mais fácil apropriação por gestores públicos.

\section{Conclusão}

A questão inicial do trabalho era a de buscar a "melhor forma" de avaliação de programas de marketing social. Essa "melhor" maneira de avaliação foi tomando forma, ao longo do desenvolvimento do trabalho, em um continuum cronológico, que parte de uma avaliação de diagnóstico, inicial, segue em uma avaliação de processo, que se convencionou chamar de formativa, e uma avaliação de resultados, ao final, normalmente designada como somativa na literatura. Entre os objetivos gerais do trabalho estavam o de identificação das categorias e variáveis da estrutura conceitual, e tal foi feito, com análise empírica da estrutura. Não obstante, os indicadores - e sua forma de mensuração — deverão ser adaptados a cada situação de uso específico da estrutura.

Como limitações do estudo, tem-se o baixo índice de respondentes da técnica Delphi, não obstante os cuidados recomendados no modus operandi de pesquisa terem sido observados. Tal fato compromete possíveis generalizações de resultados, mas, como se trata de uma pesquisa qualitativa, não se buscou generalização, tampouco validação estatística, mas antes a melhor compreensão do fenômeno de avaliação de programas sociais. Da mesma forma, embora a importância da reflexão ética sobre as ações de marketing social tenha ficado clara na pesquisa, não houve igual clareza em como se realiza, na prática, essa reflexão. Há duas linhas principais a serem seguidas - a ética do dever e a ética utilitarista —, além da linha do interesse próprio iluminado, mas não há "receitas" fáceis de como executá-las. Provavelmente, cada instituição pública deverá esposar a linha ética que lhe pareça a mais defensável, e procurar, com integridade, segui-la em suas ações.

Não obstante a complexidade da avaliação da dimensão ética na análise de programas de marketing social, o instrumento aqui apresentado é uma estrutura útil e atualizada nas 
melhores práticas para uma gestão adequada dos recursos públicos em programas desse tipo, de mudança social planejada visando o bem-estar individual e coletivo.

Resgate-se aqui o chamamento de Mowen e Minor (2004:6), de que pesquisas podem beneficiar a sociedade, "encontrando meios de influenciar as pessoas para que ajam com mais responsabilidade [...] e aplicar as descobertas da pesquisa para desenvolver tratamento e métodos preventivos que reduzam as ações mal-ajustadas dos consumidores" (ênfase acrescentada).

A estrutura conceitual pretendida e apresentada traz categorias e subcategorias para avaliação de programas de marketing social, com indicadores e modos de mensurá-los que podem auxiliar nessa tarefa. Se Wiebe, no início da década de 1950, antecipava uma oportunidade "para o marketing vender mais do que sabonete", vender antes cidadania e qualidade de vida, no estágio atual de desenvolvimento da disciplina se viu que tal é possível, apenas é o momento de se aperfeiçoar as formas de fazê-lo.

\section{Referências}

ANDREASEN, Alan. Intersector transfer of marketing knowledge. In: BLOOM, Paul N.; GUNDLACH, Gregory T. (Ed.). Handbook of marketing and society. Sage, 2000.

ANDREASEN, Alan. The life trajectory of social marketing: some implications. Marketing Theory, n. 3, p. 293-303, 2003.

ANDREASEN, Alan; ROBERT, Alan. Public health branding: applying marketing for social change. Journal of Consumer Policy, v. 32, p. 73-74, 2009.

BARDIN, Laurence. Análise de conteúdo. Lisboa: Edições 70, 1977.

BARTELS, Robert. The identity crisis in marketing. Journal of Marketing, Oct. 1974.

BATES, Cynthia. Use of social marketing concepts to evaluate ocean sustainability campaigns. Social Marketing Quarterly, v. 16, issue 1, p. 71-96, Mar. 2010.

BRENKERT, George. Ethical challenges of social marketing. Journal of Public Policy \& Marketing, v. 21, n. 1, p. 14-25, Spring 2002.

CHANCE, Zoë; DESHPANDÉ, Rohit. Putting patients first: social marketing strategies for treating HIV in developing nations. Journal of Macromarketing, v. 29, n. 3, p. 220-232, 2009.

CHEVITARESE, Leandro. Ética, serviço público e o profissional da informação. Brasília: Fundação Getulio Vargas, 22 mar./6 abr. 2010. (Curso de Formação para o Senado Federal. Apostila da FGV in Company.)

CHURCHILL JR., Gilbert A.; IACOBUCCI, Dawn. Marketing research: methodological foundations. $8^{\text {th }}$ ed. Orlando, FL: Harcourt College, 2002.

COOKSY, Leslie J. Evaluators' reflections on the ethical implications of their early experiences. American Journal of Evaluation, Dec. 2009. 
DAY, George S.; MONTGOMERY, David B. Charting new directions for marketing. Journal of Marketing, v. 63, special issue, p. 3-13, 1999.

DENZIN, Norman K.; LINCOLN, Yvonna S. (Org.). The handbook of qualitative research. $2^{\text {nd }}$ ed. Thousand Oaks, CA: Sage, 2000.

DENZIN, Norman K.; LINCOLN, Yvonna S. (Org.). O planejamento da pesquisa qualitativa: teorias e abordagens. 2. ed. Tradução de Sandra R. Netz. Porto Alegre: Bookman, 2006.

DOMEGAN, Christine T. The use of social marketing in evaluating science outreach activities in Ireland. Irish Journal of Management, p. 103-125, 2007. Disponível em: <www.highbeam.com/ doc/1P3-1429543091.html>. Acesso em: 8 fev. 2010.

DONER, Lynne. Approaches to evaluating social marketing programs. Social Marketing Quarterly, v. 9, issue 3, p. 18-26, Fall 2003.

DRUMWRIGHT, Minette E. Company advertising with a social dimension: the role of noneconomic criteria. Journal of Marketing, v. 60, n. 4, p. 71-87, Oct. 1996.

DUKE, Charles R. et al. A method for evaluating the ethics of fear appeals. Journal of Public Policy \& Marketing, Chicago, v. 12, issue 1, p. 120-129, Spring 1993.

ENRIQUEZ, Eugène. Os desafios éticos nas organizações modernas. Revista de Administração de Empresas, São Paulo, v. 37, n. 2, p. 6-17, abr./jun. 1997.

FLICK, Uwe. Uma introdução à pesquisa qualitativa. 2. ed. Tradução de Sandra Netz; revisão técnica de Teniza da Silveira. Porto Alegre: Bookman, 2004.

FONTES, Miguel. Marketing social: novos paradigmas. Rio de Janeiro: Elsevier, 2008.

FURROW, Dwight. Ética: conceitos-chave em filosofia. Porto Alegre: ArtMed, 2007.

GIL, Antonio Carlos. Métodos e técnicas de pesquisa social. 5. ed. São Paulo: Atlas, 1999.

GILL, Mel; FLYNN, Robert J.; REISSING, Elke. The governance self-assessment checklist: an instrument for assessing board effectiveness. Nonprofit Management \& Leadership, v. 15, n. 3, Spring 2005.

GORDON, Ross et al. The effectiveness of social marketing interventions for health improvement: What's the evidence? Public Health, v. 120, n. 12, p. 1133-1139, 2006.

GORDON, Ross; MOODIE, Crawford. Dead cert or long shot: the utility of social marketing in tackling problem gambling in the UK? International Journal of Nonprofit and Voluntary Sector Marketing, London, v. 14, issue 3, p. 243-253, Aug. 2009.

HAIR, Jr. et al. Fundamentos de métodos de pesquisa em administração. Porto Alegre: Bookman, 2005.

HAMPSON, Sarah E. et al. A social marketing approach to improving the nutrition of low-income women and children: an initial focus group study. Public Health Nutrition, Cambridge, v. 12, issue 9, p. 1563-1569, Sept. 2009. 
HUNT, Shelby D. Foundations of marketing theory: toward a general theory of marketing. M. E. Sharpe, 2002.

KERIN, Roger et al. Marketing. 8. ed. São Paulo: McGraw-Hill, 2008.

KIRBY, Susan B.; ANDREASEN, Alan R. Marketing ethics to social marketers: a segmented approach. In: ANDREASEN, Alan R. (Ed.). Ethics in social marketing. Washington, DC: Georgetown University Press, 2001.

KOTLER, Philip; LEE, Nancy. Marketing no setor público: um guia para um desempenho mais eficaz. Porto Alegre: Bookman, 2008.

KOTLER, Philip; ROBERTO, Eduardo L. Marketing social: estratégias para alterar o comportamento público. Rio de Janeiro: Campus, 1992.

KOTLER, Philip; ROBERTO, Eduardo L. Social marketing: strategies for changing public behavior. New York: The Free Press, 1989.

KOTLER, Philip; ROBERTO, Ned; LEE, Nancy. Social marketing: improving the quality of life. $2^{\text {nd }}$ ed. Sage, 2002.

KUNDIN, Delia M. A conceptual framework for how evaluators make everyday practice decisions. American Journal of Evaluation, June 2010.

MACHADO, Sany Karla; DAMACENA, Cláudio. Percepção dos consumidores acerca do marketing relacionado a causas: uma revisão da literatura. Base - Revista de Administração e Contabilidade da Unisinos, São Leopoldo, v. 3, n. 2, maio/ago. 2006.

McDERMOTT, Robert J. Essentials of evaluating social marketing campaigns for health behavior change. The Health Education Monograph Series, v. 21, n. 1, p. 13-20, 2004.

McGEVERAN, W. Disclosure, endorsement, and identity in social marketing. University of Illinois Law Review, v. 2009, issue 4, p. 1105-1166, 2009.

MEIRA, Paulo Ricardo dos Santos; SLONGO, Luiz Antonio. Dimensões de avaliação de programas de marketing social para a segurança do trânsito no Brasil. Revista dos Transportes Públicos, v. 118, p. 15-30, 2008.

MOWEN, John; MINOR, Michael. Comportamento do consumidor. São Paulo: Pearson \& PrenticeHall, 2004.

MURPHY, P.E.; BLOOM, P.N. Ethical issues in social marketing. In: Marketing the public sector: promoting the causes of public \& nonprofit agencies. Transaction Publishers, 1992. p. 68-78.

PEATTIE, Ken; PEATTIE, Sue. Social marketing: a pathway to consumption reduction? Journal of Business Research, v. 62, p. 260-268, 2009.

PRINGLE, Hamish; THOMSON, Marjorie. Marketing social: marketing para causas sociais e a construção das marcas. São Paulo: Makron Books, 2000.

ROSSITER, John R. What is marketing knowledge? Stage I: forms of marketing knowledge. Marketing Theory, v. 1, n. 1, p. 9-26, 2001. 
RUST, Roland T. et al. Measuring marketing productivity: current knowledge and future directions. Journal of Marketing, v. 68, p. 76-89, Oct. 2004.

SHETH, Jagdish; FRAZIER, Gary. A model of strategy mix for planned social change. Journal of Marketing, v. 46, n. 1, p. 15-26, Winter 1982.

SILVA, Edson Coutinho. A aplicação do marketing social ao planejamento, elaboração e implementação de políticas públicas de saúde. Dissertação (mestrado) — Imes, Universidade Municipal de São Caetano do Sul, São Paulo, 2005.

SMITH, Warren; HIGGINS, Matthew. Cause-related marketing: ethics and the ecstatic. Business \& Society, v. 39, n. 3, p. 304-322, Sept. 2000.

STRAUSS, Anselm; CORBIN, Juliet. Pesquisa qualitativa: técnicas e procedimentos para o desenvolvimento de teoria fundamentada. 2. ed. Porto Alegre: Artmed, 2008.

VARCOE, Jude. Assessing the effectiveness of social marketing [white paper]. Esomar, The World Association of Research Professionals, 2004. Disponível em: <http://socialmarketing.co.nz/research/AssSMMay04.pdf>. Acesso em: 20 abr. 2010.

VERGARA, Sylvia Constant. Métodos de pesquisa em administração. 3. ed. São Paulo: Atlas, 2008.

VOIGHT, Joan. Social marketing do's and don'ts. AdWeek, v. 48, issue 36, p. 14-30, 10 Aug. 2007.

WATSON, Jennifer M. et al. Effectiveness of a social marketing media campaign to reduce oral cancer racial disparities. Journal of the National Medical Association, Washington, v. 101, issue 8, p. 774-783, Aug. 2009.

WEINREICH, Nedra Kline. Hands-on social marketing: a step-by-step guide. Thousand Oaks, CA: Sage, 1999.

WIEBE, G.D. Merchandising commodities and citizenship on television. Public Opinion Quarterly, v. 15, p. 679-691, Winter 1951/2.

YIN, Robert K. Estudo de caso: planejamento e métodos. 2. ed. Porto Alegre: Bookman, 2001.

Paulo Ricardo dos Santos Meira é analista legislativo e produtor de marketing do Senado Federal. Email:paulorsm@senado.gov.br.

Cristiane Pizzutti dos Santos é professora do PPGA da Universidade Federal do Rio Grande do Sul (UFRGS).E-mail: cpsantos@ea.ufrgs.br. 